\title{
Monitoring system of vital signs at distance and in real time through IoT Technology
}

\section{Sistema de monitoreo de signos vitales a distancia y en tiempo real mediante Tecnología IoT}

GONZALEZ-LORENCE, Armida*†, AYALA-LANDEROS, José G., AMAYA-PÉREZ, Angélica J., and SÁNCHEZ-ORDUÑA, Govani G.

Instituto Tecnológico de San Juan del Río / Tecnológico Nacional de México, Ave. Tecnológico No. 2, Col. Centro, San Juan del Río, Qro. C.P. 76800

ID $1^{\text {st }}$ Author: Armida, González-Lorence / ORC ID: 0000-0001-6926-7238, CVU CONACYT ID: 200848

ID $1^{\text {st }}$ Coauthor: José G, Ayala-Landeros / ORC ID: 0000-0002-6967-5175, CVU CONACYT ID: 284339

ID $2^{\text {nd }}$ Coauthor: Angélica, J. Amaya-Pérez / ORC ID: 0000-0001-6984-4488, CVU CONACYT ID: 460608

ID $3^{\text {rd }}$ Coauthor: Govani G., Sánchez-Orduña / ORC ID: 0000-0002-1985-5282, CVU CONACYT ID: 1027502

DOI: $10.35429 / J T P .2019 .16 .5 .21 .32$

Received September 17, 2019; Accepted December 15, 2019

\begin{abstract}
This article presents the architecture, design and development of an Internet of Things (IoT) tool that performs remote and real-time monitoring of immunosuppressed terminally ill patients, who have been sent home by their doctors to wait the time of death, however, these patients usually are cared by the useful but unexperienced hands of their relatives. This tool aims to facilitate communication between the attending medic and the relative who takes care of the patient, it promotes the patient's comfort and accurate care using sensors, devices and mobile applications linked to each other. The methodology includes: the patient's characterization, in order to identify their requirements and characteristics that distinguish them; existing medical sensor's study and selection of the necessary ones. Subsequently, signals acquisition and compatibility effected for the selected sensors, and finally, the tool's design includes: Selected sensors, controllers, server, translator, databases and web application.
\end{abstract}

Internet of things, Monitoring, Health

\begin{abstract}
Resumen
Este artículo presenta la arquitectura, diseño y desarrollo de una herramienta de Internet de las Cosas (IoT) que realiza el monitoreo a distancia y en tiempo real de un paciente inmunodeprimido en etapa terminal, que ha sido enviado a su casa por los médicos tratantes para sólo esperar el momento del fallecimiento, sin embargo, dichos pacientes quedan al cuidado de las manos útiles pero inexpertas de sus familiares. Esta herramienta pretende facilitar la comunicación entre el médico tratante y el familiar que esté al cuidado del paciente, promueve la comodidad y atención adecuada del mismo, utilizando sensores, dispositivos y aplicaciones móviles relacionados todos entre sí. La metodología incluye: Caracterización de pacientes de interés, para identificar sus requerimientos y características que los distinguen, estudio de sensores médicos existentes y de éstos selección de los necesarios. Posteriormente, se efectúa la adquisición y compatibilidad de señales de los sensores, se diseña la herramienta incluyendo: Sensores elegidos, controladores, servidor, traductor, bases de datos y aplicación web. Finalmente, se realizan pruebas para comprobar ejecución, desempeño y confiabilidad del nuevo sistema de IoT desarrollado.
\end{abstract}

Internet de las Cosas, Monitoreo, Salud

Citation: GONZALEZ-LORENCE, Armida, AYALA-LANDEROS, José G., AMAYA-PÉREZ, Angélica J., and SÁNCHEZ-ORDUÑA, Govani G.. Monitoring system of vital signs at distance and in real time through IoT Technology. Journal of Technological Prototypes. 2019. 5-16: 21-32

\footnotetext{
*Correspondence to Author (email: armida.lorence@itsanjuan.edu.mx.edu.mx)

$\dagger$ Researcher contributing first author
} 


\section{Introduction}

The concept: "Internet of Things" (IoT) was coined in the early 21 st century by MIT's AutoID Center by Kevin Ashton (Ashton 2009). The IoT integrates everything: Detection, identification, communication, networks, devices and computer systems; it interconnects people with things in real time anywhere, through any device and means of communication.

The IoT promises numerous social and economic benefits not only to emerging economies but also to developing economies. The IoT promises an "intelligent" world, fully interconnected, constantly advancing, efficient and with great opportunities which will result in billions for industry and the global economy (Thierer, 2018).

It is expected that by 2020 more than $65 \%$ of companies (up to $30 \%$ today) will adopt IoT products (Gartner, 2017). Gartner predicts that by 2021 , less than $1 \%$ of motorway transport will be made up of autonomous trucks, but if we consider that there are 3.6 million vehicles, then that means that within five years there could be up to 36,000 autonomous trucks traveling on the roads.

In addition, Huawei asserts that in 2025 there will be 100 billion connections to IoT (Huawei, 2018) and the McKinsey Global Institute believes that the financial impact of IoT on the global economy could be 3.9 to 11.1 billion dollars in 2025 (Manyika, 2015), which shows a significant influence and growth for the IoT.

In this sense, the IoT offers promising solutions for health care, since it is possible to consider the care and maintenance of medical equipment, the registration and control of medical assets in hospitals, as well as the care, control and supervision of patients.

Thus, the Internet-of-Things (IoT) based home health care services, which is the ultimate goal of this research, have great potential in the health care field.

\section{Background}

The IoT delivers a data source which provides embedded sensors and actuators (Arriarán Rooms, 2015) that allow the capture, storage and management of information emitted by these objects in order to automate daily life activities and processes. Today, the IoT encompasses virtually everything, such as: security and autonomous control systems for homes (postscapes, 2018), control and monitoring systems for shops, banks, restaurants (Meola, 2018), energy management and security systems in office buildings (Wesson, 2018), production environments (Abdulla, 2017), systems for monitoring and control of mining, oil and gas, construction (Meola, 2018), moving vehicles such as automobiles, trucks, ships, airplanes and trains (Meola, 2018), adaptive traffic control systems, intelligent meters and environmental monitoring (Fischione, 2016). There are even IoT devices attached to the human body to monitor and maintain people's health, fitness and well-being (Farooq, Waseem, Mazhar, Anjum, \& Kamal, 2015).

\section{The IoT and health}

Improving human health and well-being is anyone's primary purpose, so health care systems around the world are vitally important.

For a decade, hospitals have endeavored to be equipped with RFID tagging technology, tagging patients so that doctors and nurses can monitor their heart rate, blood pressure, temperature and other conditions (Fuhrer, 2006). The internet-of-Things (IoT) offers promising health care solutions focusing on the care and maintenance of medical equipment, the recording and control of medical assets, and most importantly, the care, control and supervision of patients.

These are some of the most important works that have been developed previously: The patent WO2009/022320A2 (Colombia Patent No. WO2009022320A2, 2009), it is a system that integrates the functions of basic equipment for monitoring patients in intensive care or critical condition, in which the monitoring and transfer of patients should be performed only by highly trained personnel due to the complexity of the technology that can be understood only by medical specialists. 
Patent WO2014/163475A1 (Mexico Patent No. WO 2014/163475 A1, 2014), it is a telemedicine operating system with various devices that connect to the patient and generate medical information transmitted to the specialist, who can make a diagnosis and propose a medical treatment for the patient who is in a remote location. However, it does not work in real time. It is necessary to emphasize that the intention of the work proposed here is the monitoring of vital signs and resolution of problems in real time of a patient who is being treated at home, with the help of relatives without medical knowledge, providing comfort to such relatives, since they have a fast, timely and effective monitoring system to care for their patient.

\section{Justification}

At present there are situations concerning health care which are impossible to develop in a traditional way, due to the natural growth of population and the evolution of humanity. Therefore, the technological possibilities of the IoT can be exploited.

Through the development of this research, it has been possible to distinguish and solve a series of problems on device architectures, sensors and system integration, which necessarily appear in the initial stage of development of any technology, because the applications of IoT are not fully implemented as of today.

It must be considered that currently there are too many medical treatments that for most patients are unreachable, either because of difficult access to hospitals, excessive hospitalization costs, or because they require long and expensive transfers. Research like this, focusing on the use of IoT technologies in the area of health, will bring these treatments to anyone regardless of their geographical and economic situation.

For this reason, an application of the IoT has been developed to treat terminally ill patients cared at home, to help the patient's well-being, as well as appropriate and real time care, and to provide comfort and adequate information to the family members assigned to their care; consequently, it will favor the family economy by avoiding hospitalization expenses and payment of specialists.

\section{Hypothesis}

By using a monitoring system based on IoT technology, real-time care and control of immunocompromised patients whose health is characterized as delicate but stable and who are in a terminal stage will be facilitated.

\section{Objective}

To design and develop an IoT tool, through the integration of various sensors and devices, to monitor, control and provide treatment in real time; to improve the medical care offered by doctors, family and staff assigned to the care of an immunocompromised patient, delicate but stable, in terminal stage staying at home (see figure 1).

\section{Procedure and description of the activities}

The activities carried out during the development of this research are described below:

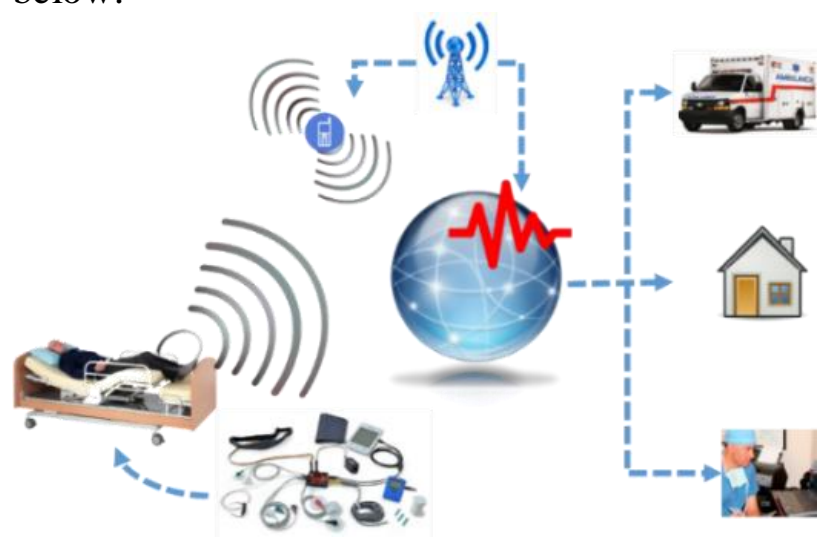

Figure 1 IoT tool, monitoring from home (Prepared by the authors)

\section{Patient Characterization}

The patients for whom this IoT system has been designed are in terminal stage conditions, so their doctors have sent them to their homes to be cared for, so that they may have the opportunity, in this final stage, to be close to all their loved ones; they are patients who mainly come from long processes of suffering and lack of control with a high mortality rate.

Patients suffering from Diabetes Mellitus, a disease that can give rise to many illnesses which at times dehydration should be strictly monitored and keep the patient asymptomatic and controlled while blood glucose numbers remain between 150 and 250 mg/dl (Cortés Bejar, 2016).

GONZALEZ-LORENCE, Armida, AYALA-LANDEROS, José G., AMAYA-PÉREZ, Angélica J., and SÁNCHEZ-ORDUÑA, Govani G.. Monitoring system of vital signs at distance and in real time through IoT Technology. Journal of Technological Prototypes. 2019 
Terminal AIDS patients who require constant control of pain, hydration, nutrition, skin care, recurrent infections and agitation. Patients with Arterial Hypertension, in the advanced stages of the disease patients are placed in terminal stage situations where monitoring of blood pressure and heart rate is indispensable.

Heart failure is a progressive, lethal disease, with many symptoms, which affects a large part of the population, although some patients may suffer sudden death due to cardiac arrhythmia, most die from progressive failure. The economic impact of heart failure is high and almost all resources are spent in the last six months of a patient's life. For patients with these diseases, blood pressure, heart rate, respiratory rate, pulse, and temperature should be monitored.

Cancer can affect people of all ages, causing about $13 \%$ of all deaths according to the American Cancer Society (Society, 2019). Cancer is very serious due to its ability to spread throughout the body, producing metastatic cancer, with treatments for its side effects, mainly consisting of pain control (symptom that can be identified through body sweating), and also, depending on the type of cancer the patient presents, they will also require assistance in breathing, body position, temperature control and heart rate.

The IoT monitoring system developed in this research can be used to send and receive reliable data in real time between doctors and caregivers of the patient, thus facilitating comfort and timely care for the patient.

\section{Selection of sensors for measuring vital signs}

The sensors were specifically selected for the monitoring of the essential vital signs which must be tracked during terminal stage situations, assigning priority according to the advice provided by the doctor Enrique Araujo Vargas (professional card: 5102204), which are listed in order of importance below:

\section{- Body temperature sensor \\ - Blood Glucose Sensor \\ - Electrocardiogram sensor \\ - Cardiac pulse sensor}

Initially, we identified and researched the vital sign sensors existing in the market and from there, we selected the most suitables for the project.

\section{DS18B20 Temperature Sensor}

The DS18B20 temperature sensor (figure 2) accurately measures the temperature and provides an output of alarm/interruption/stop of temperature, it can measure temperatures between $-55^{\circ} \mathrm{C}$ and $125^{\circ} \mathrm{C}$. (Maxim Integrated, 2018).

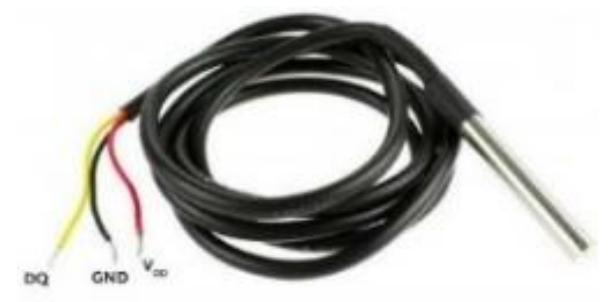

Figure 2 DS18B20 Sensor

(Maxim Integrated, 2018)

This sensor allows its integration with most existing controllers, its accuracy, low power consumption and operating range are in line with the needs of a project dedicated to the health field (Maxim Integrated, 2018).

\section{MAX30100 Pulse and Oxygen Sensor}

The MAX30100 (figure 3), contains an oximetry pulse and a heart rate integrated in the same sensor (Maxim Integrated, 2018).

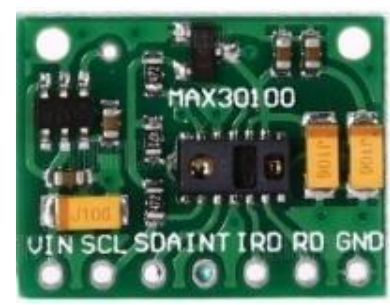

Figure 3. MAX30100 Sensor (Maxim Integrated, 2018)

It has been chosen for its small size of only $5.6 \mathrm{~mm} \times 2.8 \mathrm{~mm} \times 1.2 \mathrm{~mm}, 14$ pins, low power consumption, programmable sample rate and energy-saving LED current.

Its advanced functionality improves the measurement procedure, has high resistance to robust motion, and fast data output capability. 


\section{Heart Rate Sensor}

The AD8232 sensor (figure 4) is a block of integrated signals necessary for ECG (Electro cardiogram), useful for measuring the electrical activity of the heart and other applications of electrical measurements of the human body (biopotentials).

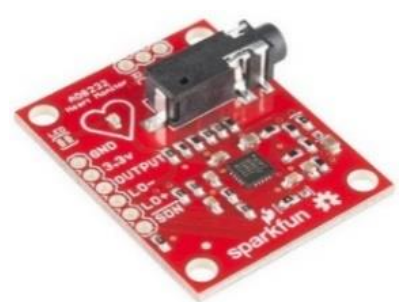

Figure 4. Heart Rate Sensor

(Maxim Integrated, 2018)

\section{Blood oxygenation and pulse sensor}

This sensor (Figure 5) is used to measure pulse oximetry which is a non-invasive method of indicating arterial oxygen saturation of functional haemoglobin. Oxygenated and deoxygenated hemoglobin absorb different wavelengths.

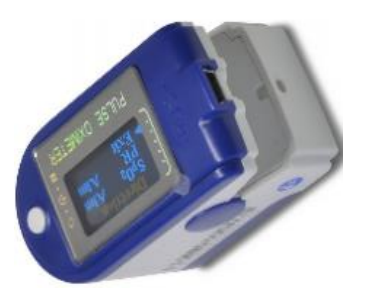

Figure 5. Blood oxygenation and pulse sensor (Libelium Sistemas Distribuidos, 2018)

Normal acceptable ranges for patients are 95-99\%, ranges with hypoxia conduction problems $88-94 \%$, values of $100 \%$ may indicate carbon monoxide poisoning.

\section{EMG electromyography sensor}

This sensor (figure 6) detects the electrical potential generated by muscle cells when these are activated electrically or neurologically. The signals can be analyzed to detect medical abnormalities in the biomechanics of human or animal movement. (Libelium Distributed Systems, 2018)

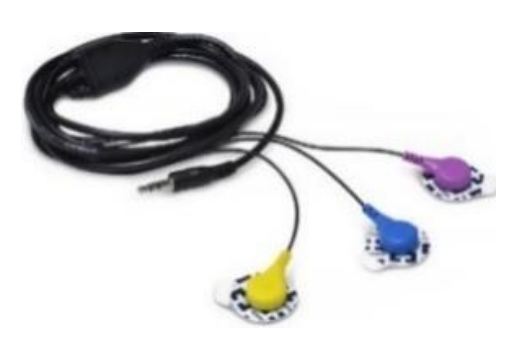

Figure 6 Electromyography sensor (Libelium Sistemas Distribuidos, 2018)

This sensor measures the filtered and rectified electrical activity of a muscle, depending on the amount of activity in the selected muscle.

\section{Blood Glucose Sensor}

The glucose sensor (Figure 7) is used to determine the concentration of glucose in the blood. For the type of patients characterized in this research, continuous monitoring of their glucose readings is of paramount importance.

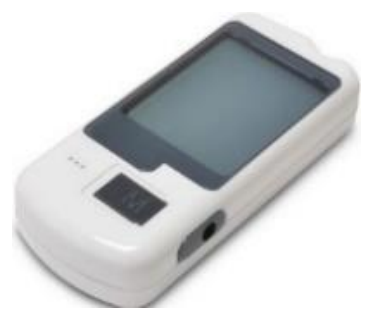

Figure 7. Glucose Sensor

(Libelium Sistemas Distribuidos, 2018) $\mathrm{mmol} / \mathrm{L}$.

The meter displays the level in $\mathrm{mg} / \mathrm{dL}$ or

\section{Body Position Sensor}

This sensor controls five different patient positions (standing/sitting, supine, face down, right and left; see figure 8 and figure 9). (Libelium Distributed Systems, 2018).

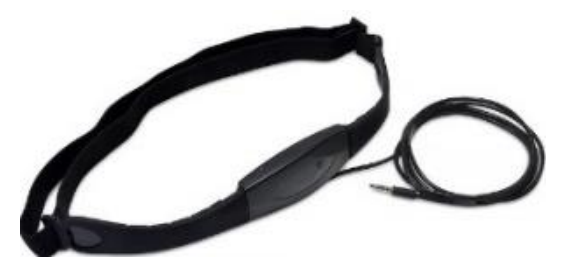

Figure 8. Body Position Sensor (Maxim Integrated, 2018) 


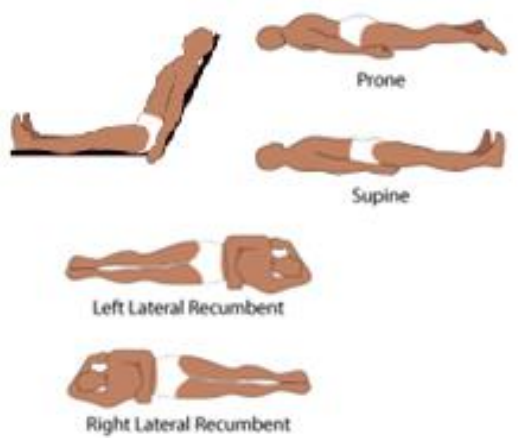

Figure 9 Positions detectable by the sensor (Maxim Integrated, 2018)

It uses a triple-axis accelerometer to obtain the patient's position. It is an ultra-small low-gravity device, which allows the measurement of accelerations in 3 perpendicular axes to identify the sensations of inclination, movement, shock and vibration.

\section{ECG electrocardiogram sensor}

The electrocardiogram (ECG, Figure 10) is a diagnostic tool used to evaluate the heart's muscle functions. It uses "continuous telemetry electrocardiogram" over a long period of time.

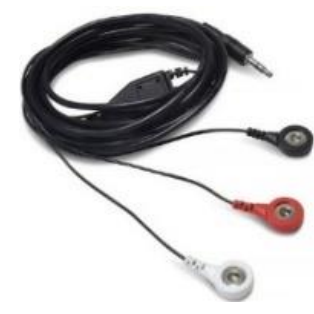

Figure 10 ECG Sensor

(Libelium Sistemas Distribuidos, 2018)

This sensor uses high quality disposable pre-gelified electrodes to measure EEG, ECG and EMG.

\section{Galvanic Skin Response Sensor}

The galvanic skin response sensor (Figure 11) measures the electrical conductance of the skin, which varies with its moisture level. This is of interest because the sweat glands are controlled by the sympathetic nervous system. Drier skin registers a much higher resistance (Libelium Distributed Systems, 2018).

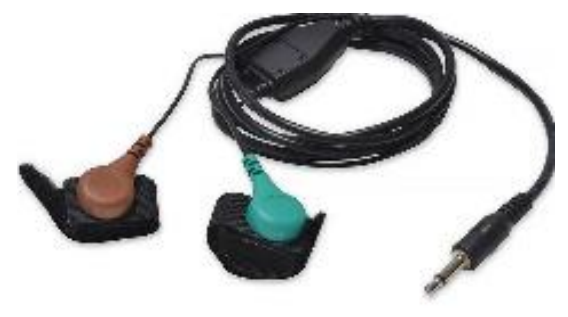

Figure 11 Galvanic Skin Sensor (Libelium Sistemas Distribuidos, 2018).

Emotions such as pain, excitement, stress, shock, etc. can cause the skin's conductivity to fluctuate.

\section{Airflow Breathing Sensor}

Abnormal respiratory rates and changes in respiratory rate are a broad indicator of greater physiological instability, with this sensor (Figure 12) it is possible to monitor respiratory rate as an indicator of patient status.

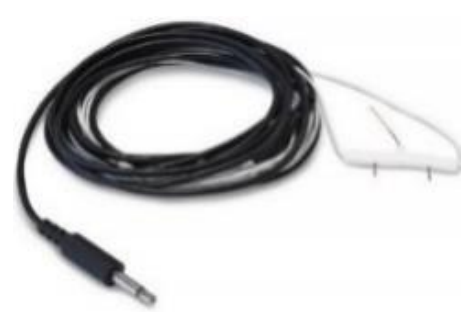

Figure 12 Air Flow Sensor (Maxim Integrated, 2018)

The AirFlow sensor can provide early warning of hypoxemia and apnea, it is used to measure the respiratory rate in a patient needing respiratory assistance.

\section{Body temperature sensor}

By means of the D-S18JK sensor (figure 13) the indispensable body temperature is monitored, because several illnesses are accompanied by characteristic changes in the corporal temperature, in fact, the course of certain diseases is made by measuring the aforementioned temperature.

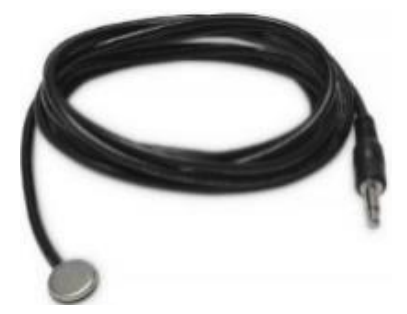

Figure 13 Body Temperature Sensor (Maxim Integrated, 2018) 


\section{Connection between the different IoT sensors and devices}

The devices and sensors are connected under the MQTT protocol (MQTT, 2018), which offers advantages over other protocols, we also used the standard 802.11 (WiFi) for communication between the controller and the server.

\section{Priority and importance of vital signs to be} measured in patients

According to the importance given to vital signs for the monitoring of the diseases mentioned, we chose to start with the following sensors:

\section{- $\quad$ Body temperature \\ - Heart rate \\ - $\quad$ Oximetry MAX30100}

\section{Design of the IoT tool for patient monitoring}

Figure 14 shows the design of the IoT tool, which consists of the following elements:
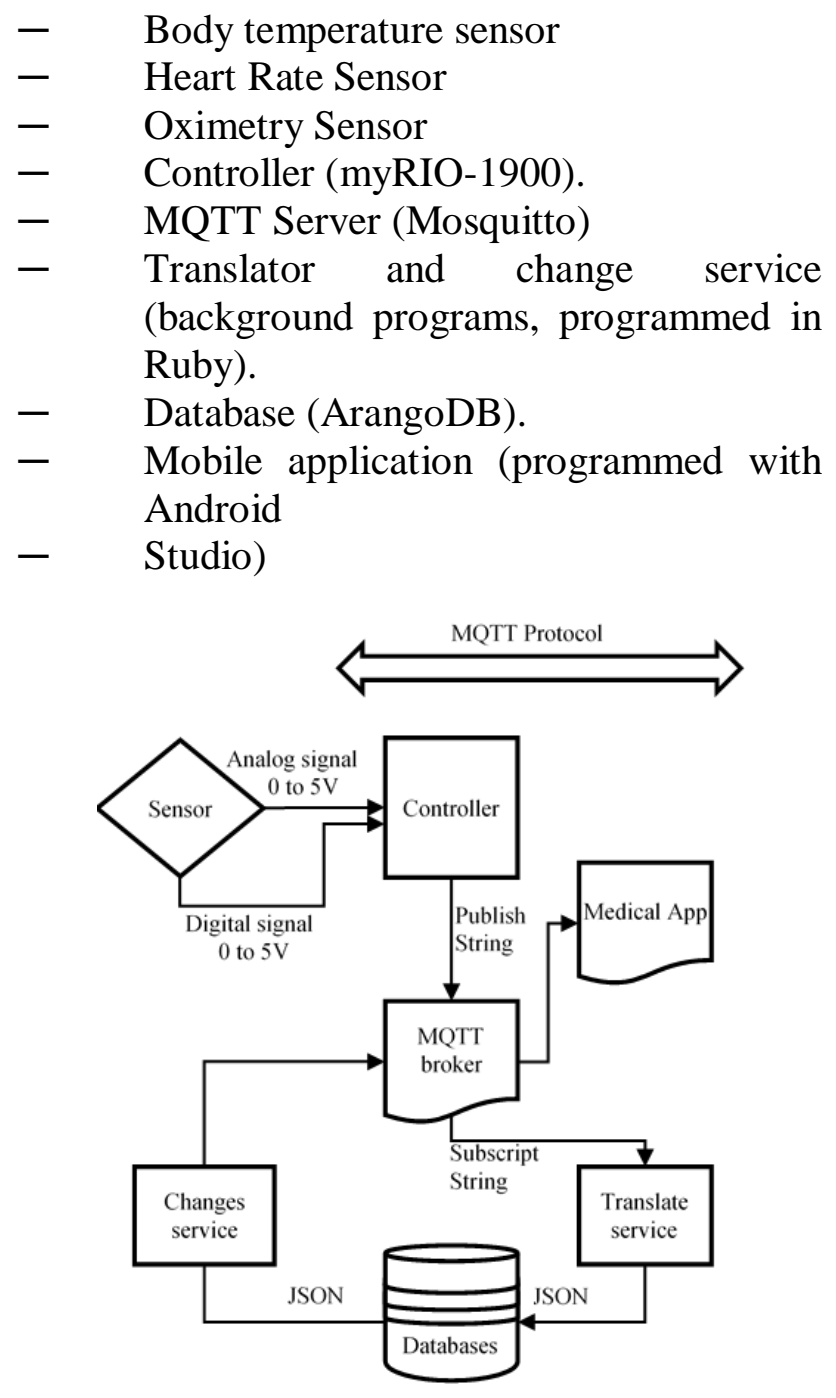

Figure 14 General system diagram (Prepared by the authors)
The operation consists of sending a pulse from the sensor to the controller, which interprets the signal and sends it through the network to the MQTT server, which retransmits the message to subscribers. The translator program is in charge of giving it the JSON format so that it can be interpreted correctly by the database.

There is another service running continuously that immediately identifies any alteration in the database, and reports in real time via MQTT to the application of the patient and the doctor. In the same way, this last service allows the pertinent queries to be made to the database.

\section{Configuration and integration of selected IoT devices and sensors}

Initially, the readings of the chosen sensors are acquired and the configuration of the prototype is carried out. The DS18B20 temperature sensor, the MAX30100 oximetry sensor and the GY-61 cardiac pulse sensor are connected with the Arduino MEGA 2560 ATMEGA components, Shield Ethernet for Arduino, Router with LAN ports (figure 15).

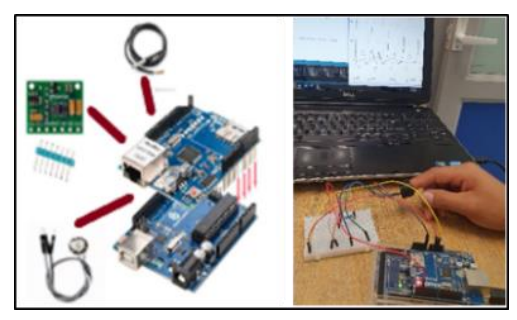

Figure 15. Integration of Devices and Sensors (Prepared by the authors)

The corresponding connection diagram for the temperature sensor is shown in figure 16 .

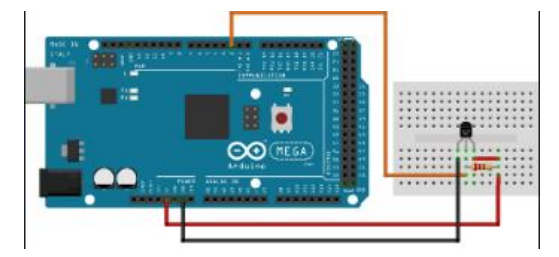

Figure 16 DS18B20 Temperature Sensor (Prepared by the authors)

Taking as reference the flat part of the DS18B20 temperature sensor, on the left is the GND ground output, on the center is the data output that can go to a digital or analog pin and the right should go to $5 \mathrm{v}$ current.

GONZALEZ-LORENCE, Armida, AYALA-LANDEROS, José G., AMAYA-PÉREZ, Angélica J., and SÁNCHEZ-ORDUÑA, Govani G.. Monitoring system of vital signs at distance and in real time through IoT Technology. Journal of Technological Prototypes. 2019 
3 male/female wires are inserted into the sensor terminals, the central pin is located on digital pin 2 of the board (or it could also be tapped directly to the proto as shown in the diagram). The resistance greater than or equal to $4.7 \mathrm{KOhms}$ is placed between the current pin and the digital pin (pullup), in order to protect the sensor from a high voltage.

The corresponding wiring diagram for the oximetry sensor can be seen in Figure 17.

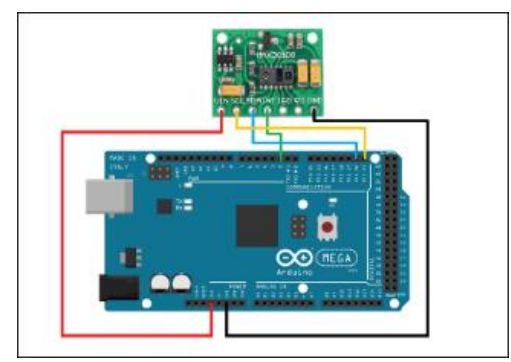

Figure 17 Oximetry Sensor

(Prepared by the authors)

The sensor has the name of each terminal printed on the front: VIN, SCL, SDA, INT, IRD, $\mathrm{RD}$ and GND. A male/female cable is placed on each of its outputs and associated with the arduino according to table 1 :

\begin{tabular}{|l|l|}
\hline AD8232 Sensor & Arduino MEGA \\
\hline VIN & $3.3 \mathrm{v} / 5 \mathrm{v}$ \\
\hline SCL & SCL/21 \\
\hline SDA & SDA/20 \\
\hline INT & Digital pin 2 \\
\hline IRD & ----------- \\
\hline RD & ---------- \\
\hline GND & GND \\
\hline
\end{tabular}

Table 1 Oximeter Terminals (Prepared by the authors)

Regarding the electrocardiogram sensor, the corresponding wiring diagram is presented in (figure 18).

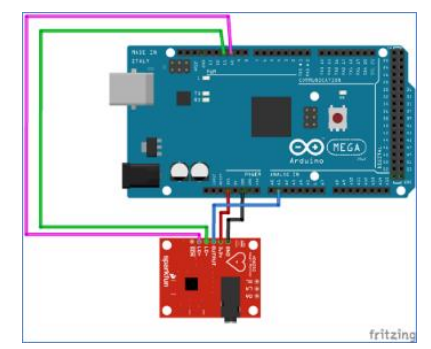

Figure 18 Electrocardiogram sensor Prepared by the authors
The sensor has printed on the front the name of each of the terminals: GND, $3.3 \mathrm{v}$, OUTPUT, LO-, LO+ and SDN, a male/female cable is placed in each of its outputs as shown in table 2:

\begin{tabular}{|l|l|}
\hline AD8232 Sensor & Arduino MEGA \\
\hline GND & GND \\
\hline $3.3 \mathrm{v}$ & $3.3 \mathrm{v}$ \\
\hline OUTPUT & Analog Pin 1 (A1) \\
\hline LO- & Digital pin 11 \\
\hline LO+ & Digital pin 10 \\
\hline SDN & ----------- \\
\hline
\end{tabular}

Table 2 Electrocardiogram terminals. Prepared by the authors

The connection of the AD8232 cables is indicated on the plastic end (depending on the manufacturer colors may vary), the RA (Right Arm) cable should be placed on the right chest, the LA (Left Arm) cable under the heart area and the RL (Right Leg) cable on the right side (Figure 19).

The sensor has a $3.5 \mathrm{~mm}$ input to connect the cable that combines each of the 3 inputs where the electrodes are placed on the patient's body.

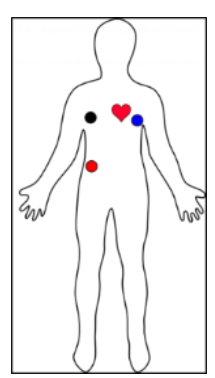

Figure 19 Position of electrocardiogram connections Prepared by the authors

\section{Application of the System and its functions}

The software system developed consists of a web application that performs the control, acquisition and processing of data, and updates the system in real time, allowing the doctor to immediately have the current information of the patients. In figure 20, the medical screen is presented, where the doctor can immediately see the situation of the patients, facilitating instant attention to the patient who requires it. It is possible to view and search information in alphabetical order and visualize the name of the patient, along with the reading of each of their vital signs. 


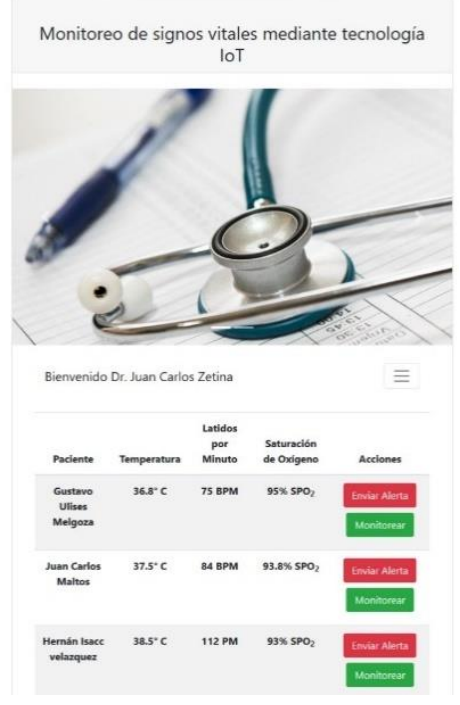

Figure 20 Medical Screen

Prepared by the authors

Also, a red action option (red button) was implemented to send the patient's relative an immediate indication regarded as necessary at that time, figure 21.

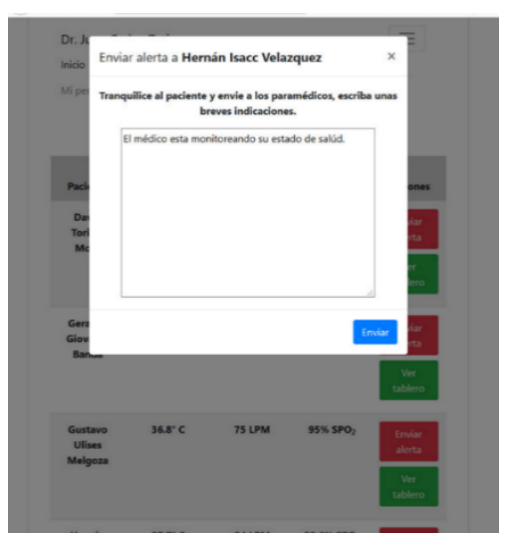

Figure 21 Sending a message to the patient's caregiver Prepared by the authors

Likewise, a green action (green button) appears to access the historical situation of each patient (figure 22).

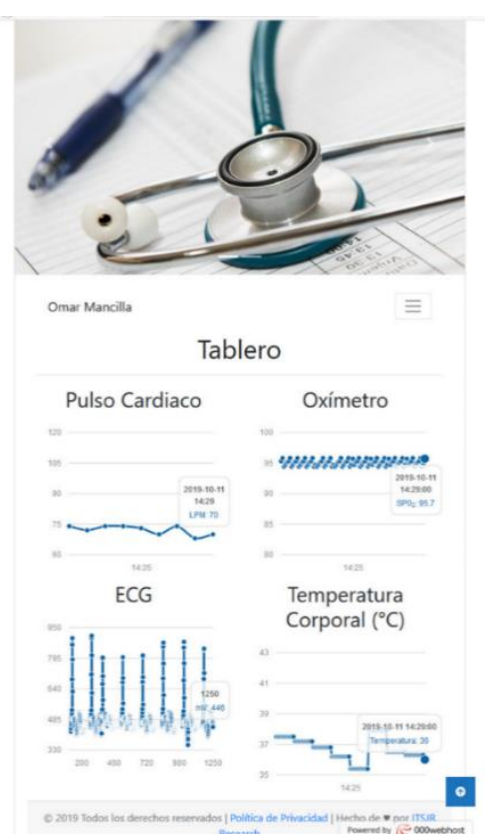

Figure 22 Patient History

Prepared by the authors

The medical screen (figure 20) has a drop-down menu as shown in figure 23 , for changing passwords, logging out or adding patients.

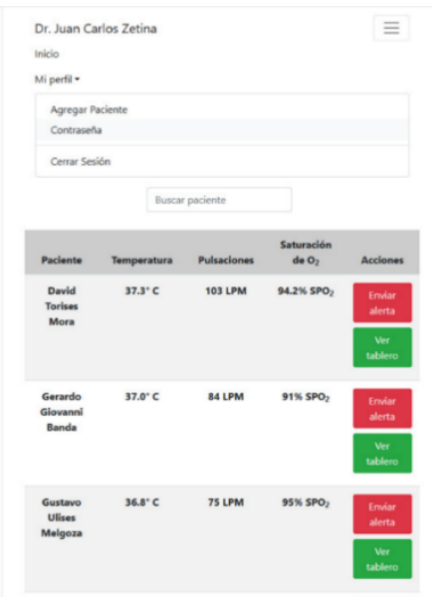

Figure 23 Medical-screen drop-down menu Prepared by the authors

On the other hand, on the patient's screen it is possible to see the personal data and graphs of the behaviour of the readings of the sensors connected to them, as it is seen from the doctor's application, (figure 24). 


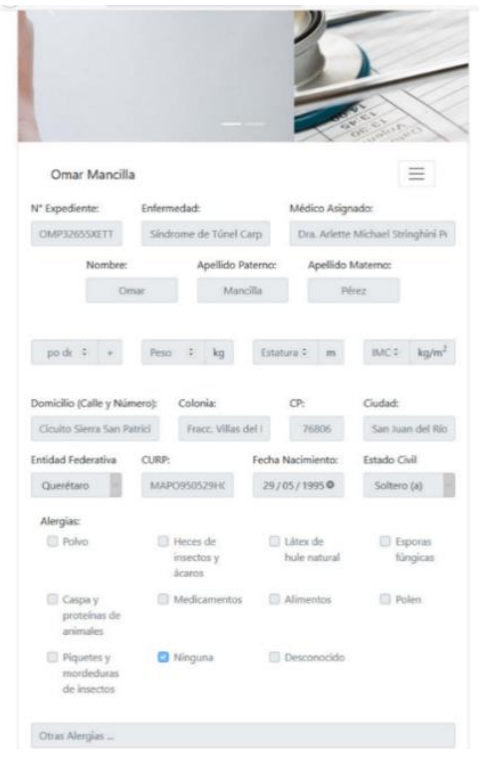

Figure 24 Patient Information

Prepared by the authors

The important part of the patient is that when any sensor detects an abnormal reading, it sends an immediate alert (in real time) to the doctor, requesting instant attention, (figure 25).

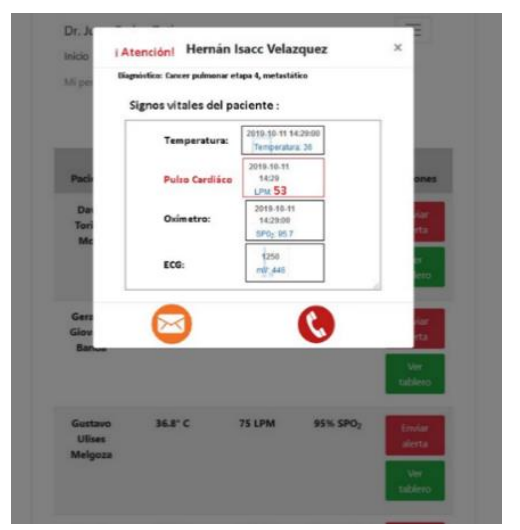

Figure 25 Alert the doctor, requesting immediate attention to the patient

Prepared by the authors

By means of the previous request, the doctor can send indications to the patient's family member, thus making them know that if the doctor does not observe any extra indications, it means that the patient is as well attended and comfortable as possible.

\section{Results}

Table 3 shows the values received from each patient in real time, the latency time is not significant, the continuous readings of the sensors are presented to the doctor in maximum three minutes; it has been observed that the transmission of the reading of each vital sign is immediate.

\begin{tabular}{|r|c|c|c|c|c|}
\multicolumn{1}{r|}{ Patient ID } & Date & Hour & Arduino & MongoDB & Web \\
\hline 10025 & $11 / 10 / 19$ & $14: 21$ & $14: 21: 05$ & $14: 21: 05$ & $14: 21: 08$ \\
\hline 10045 & $11 / 10 / 19$ & $14: 21$ & $14: 21: 05$ & $14: 21: 05$ & $14: 21: 08$ \\
\hline 10063 & $11 / 10 / 19$ & $14: 21$ & $14: 21: 05$ & $14: 21: 05$ & $14: 21: 08$ \\
\hline 11247 & $11 / 10 / 19$ & $14: 21$ & $14: 21: 05$ & $14: 21: 05$ & $14: 21: 08$ \\
\hline 11533 & $11 / 10 / 19$ & $14: 21$ & $14: 21: 05$ & $14: 21: 05$ & $14: 21: 08$ \\
\hline 157 & $11 / 10 / 19$ & $14: 21$ & $14: 21: 05$ & $14: 21: 05$ & $14: 21: 08$ \\
\hline 2154 & $11 / 10 / 19$ & $14: 21$ & $14: 21: 05$ & $14: 21: 05$ & $14: 21: 08$ \\
\hline 68 & $11 / 10 / 19$ & $14: 21$ & $14: 21: 05$ & $14: 21: 05$ & $14: 21: 08$ \\
\hline 5473 & $11 / 10 / 19$ & $14: 21$ & $14: 21: 05$ & $14: 21: 05$ & $14: 21: 08$ \\
\hline 7001 & $11 / 10 / 19$ & $14: 21$ & $14: 21: 05$ & $14: 21: 05$ & $14: 21: 08$ \\
\hline 821 & $11 / 10 / 19$ & $14: 21$ & $14: 21: 05$ & $14: 21: 05$ & $14: 21: 08$ \\
\hline 10025 & $11 / 10 / 19$ & $14: 22$ & $14: 22: 05$ & $14: 22: 05$ & $14: 22: 08$ \\
\hline 10045 & $11 / 10 / 19$ & $14: 22$ & $14: 22: 05$ & $14: 22: 05$ & $14: 22: 08$ \\
\hline 10063 & $11 / 10 / 19$ & $14: 22$ & $14: 22: 05$ & $14: 22: 05$ & $14: 22: 08$ \\
\hline 11247 & $11 / 10 / 19$ & $14: 22$ & $14: 22: 05$ & $14: 22: 05$ & $14: 22: 08$ \\
\hline 11533 & $11 / 10 / 19$ & $14: 22$ & $14: 22: 05$ & $14: 22: 05$ & $14: 22: 08$ \\
\hline 157 & $11 / 10 / 19$ & $14: 22$ & $14: 22: 05$ & $14: 22: 05$ & $14: 22: 08$ \\
\hline 2154 & $11 / 10 / 19$ & $14: 22$ & $14: 22: 05$ & $14: 22: 05$ & $14: 22: 08$ \\
\hline 68 & $11 / 10 / 19$ & $14: 22$ & $14: 22: 05$ & $14: 22: 05$ & $14: 22: 08$ \\
\hline 5473 & $11 / 10 / 19$ & $14: 22$ & $14: 22: 05$ & $14: 22: 05$ & $14: 22: 08$ \\
\hline 7001 & $11 / 10 / 19$ & $14: 22$ & $14: 22: 05$ & $14: 22: 05$ & $14: 22: 08$ \\
\hline 821 & $11 / 10 / 19$ & $14: 22$ & $14: 22: 05$ & $14: 22: 05$ & $14: 22: 08$ \\
\hline 10025 & $11 / 10 / 19$ & $14: 23$ & $14: 23: 05$ & $14: 23: 05$ & $14: 23: 08$ \\
\hline 10045 & $11 / 10 / 19$ & $14: 23$ & $14: 23: 05$ & $14: 23: 05$ & $14: 23: 08$ \\
\hline 10063 & $11 / 10 / 19$ & $14: 23$ & $14: 23: 05$ & $14: 23: 05$ & $14: 23: 08$ \\
\hline 11247 & $11 / 10 / 19$ & $14: 23$ & $14: 23: 05$ & $14: 23: 05$ & $14: 23: 08$ \\
\hline 11533 & $11 / 10 / 19$ & $14: 23$ & $14: 23: 05$ & $14: 23: 05$ & $14: 23: 08$ \\
\hline 157 & $11 / 10 / 19$ & $14: 23$ & $14: 23: 05$ & $14: 23: 05$ & $14: 23: 08$ \\
\hline 2154 & $11 / 10 / 19$ & $14: 23$ & $14: 23: 05$ & $14: 23: 05$ & $14: 23: 08$ \\
\hline 68 & $11 / 10 / 19$ & $14: 23$ & $14: 23: 05$ & $14: 23: 05$ & $14: 23: 08$ \\
\hline 5473 & $11 / 10 / 19$ & $14: 23$ & $14: 23: 05$ & $14: 23: 05$ & $14: 23: 08$ \\
\hline 7001 & $11 / 10 / 19$ & $14: 23$ & $14: 23: 05$ & $14: 23: 05$ & $14: 23: 08$ \\
\hline 821 & $11 / 10 / 19$ & $14: 23$ & $14: 23: 05$ & $14: 23: 05$ & $14: 23: 08$ \\
\hline & & & & &
\end{tabular}

Table 3 Real-time value figures Prepared by the authors

It is evident that the execution of this system is done in real time, the reception of alerts and data could only be affected by the behavior of communication networks, and not by the system developed in this investigation.

\section{Acknowledgments}

The authors express their gratitude to the Tecnológico Nacional de México/Instituto Tecnológico de San Juan del Río for their collaboration and financial support for the acquisition of materials and resources necessary for the development of this research that obtained the TecNM Registry No. "SJR-PYR2019-5194. They are also grateful for the medical advice provided by Dr. Enrique Araujo Vargas and the collaboration of Omar Mancilla Pérez, a student in Computer Systems Engineering at ITSJR/TecNM. 


\section{Conclusions}

The care required for the patients characterized in this research is decisive and must be immediate, to ensure the best possible quality of life. Patients and their families often have uncertainty about whether they are being cared for in a timely and appropriate manner at this late stage of life.

Having full confidence that patients are receiving the best physical care can help them live more fully, and thus better manage the emotional side of their situation.

Through the use of this tool for monitoring patients in real time with the immediate attention of the treating physician, family members assigned to the patient's care can be sure that the best medical attention is received, freeing them from stress about any unexpected situation they might face derived from the patient's illness, and allowing them to have timely information in real time about what measures to take when the patient requires some type of assistance.

The development of this work certainly includes only a few sensors for monitoring the patient, however, we considered all sensors suitable for reading the vital signs of patients and in a later work, we propose to incorporate them and thus complement the prototype, seeking to detect any present situation for real time assistance for the patient in terminal phase.

According to medical comments, this tool will diminish the tension of the doctor when trying to offer care and attention to this type of patients. Family members gain the advantage that the physician is continuously monitoring their patient's health parameters.

\section{References}

Abdulla , F. (2017). Role of IoT and Digital technology in Textile Industry. CIO Review (India Edition).

Cortés Bejar, M. M. (2016). Atención a una persona con diabetes en fase paliativa. Diabetes Práctica, 169-224.

Espinosa Escalona, F. P., Iglesias Ramos, C. G., \& Morales Medel, A. (2014). México Patent No. WO 2014/163475 Al.
Farooq, M., Waseem, M., Mazhar, S., Anjum, K., \& Kamal, T. (2015). A Review on Internet of Things (IoT). International Journal of Computer Applications, volume 113.

Fischione, C. (2016, noviembre 2-3). KTH Royal Institute of Technology. Stockholm. Retrieved from http://www.ee.kth.se/ carlofi/

Fuhrer, P., \& Guinard, D. (2006). Building a Smart Hospital using RFID.

Gartner. (2017). Gartner Insights on How to Lead. Worldwide: Mark Hung, Gartner Research Vice President. Retrieved from Leading the IoT.

Huawei. (2018, febrero 12). "Global Connectivity Index.". Retrieved from Huawei Technologies Co.: http://www.huawei.com/minisite/gci/en/ index.html

Libelium Sistemas Distribuidos. (2018, Septiembre 27). Libelium. Retrieved from Libelium:

http://www.libelium.com/downloads/document ation/mysignals_technical_guide.pdf

Mantilla Prada, O. A., Flores Barrera, J. I., Rodríguez Pacheco, J. H., \& Ruiz Arias, C. L. (2009). Colombia Patente $n^{o}$ WO2009022320A2.

Manyika, J., Chui, M., Bisson, P., Woetzel, J., Dobbs, R., Bughin, J., \& Dan, A. (2015, Junio). The Internet of Things: Mapping the Value Beyond the Hype. Retrieved from McKinsey Global Institute.

Maxim Integrated. (2018, Septiembre 20). www.maximintegrated.com. Retrieved from https://www.maximintegrated.com/en/products/ sensors/MAX30205.html

Meola , A. (2018, 4 3). Retrieved from Internet of Things devices, applications \& examples: http://www.businessinsider.com/internet-ofthings-devices-applications-examples-2016-8

MQTT. (2018, Septiembre 7). mqtt.org. Retrieved from http://mqtt.org/faq

GONZALEZ-LORENCE, Armida, AYALA-LANDEROS, José G., AMAYA-PÉREZ, Angélica J., and SÁNCHEZ-ORDUÑA, Govani G.. Monitoring system of vital signs at distance and in real time through IoT Technology. Journal of Technological Prototypes. 2019 
postscapes. (2018, 3 4). Postcapes IoT Home Guide. Retrieved from https://www.postscapes.com/ internet-of-thingsaward/connected-home-products/

Salas Arriarán, S. (2015). Todo sobre sistemas embebidos. Lima, Perú: Universidad Peruana de Ciencias Aplicadas (UPC).

Society, A. C. (2019, agosto 12). American Cancer Society. Retrieved from https://www.cancer.org

Thierer, A. (13 de febrero de 2018). Projecting the Growth and Economic Impact of The Internet of Things. Retrieved from George: http://mercatus.org/sites/default/files/IoT-EPv3.pdf

Wesson, M. (2018, 4 4). The intelligent office: how the internet of things will revolutionize your workplace. Retrieved from https://qz.com/256041/the-intelligent-officehow-the-internet-of-things-will-revolutionizeyour-workplace/ 